\title{
TREATMENT OF SO-CALLED PALINDROMIC RHEUMATISM WITH GOLD COMPOUNDS
}

\author{
BY \\ EDWARD W. BOLAND and NATHAN E. HEADLEY \\ Los Angeles, California
}

A relatively rare form of arthritis was described by Hench and Rosenberg in 1941 and in 1944 . The syndrome is characterized by frequently recurring attacks of pain, swelling, redness, and disability involving usually one joint at a time, but sometimes multiple joints. The attacks last for short periods and then subside completely without leaving joint residue. They considered it to be a " new disease ", an entity separate from rheumatoid arthritis and distinguishable clinically from other forms of recurring acute arthritis. To this syndrome the name " palindromic rheumatism" was applied.

From an analysis of their thirty-four cases, Hench and Rosenberg outlined the clinical characteristics of palindromic rheumatism. In summary, these were as follows: (1) multiple afebrile attacks of acute arthritis characterized by pain, swelling, tenderness, varying degrees of redness, and increased local heat; (2) frequent recurrences (88 per cent. of cases averaging twenty-three attacks per year) at irregular intervals (few hours to two weeks in most cases); (3) attacks of short duration (80 per cent. lasting a few hours to three days); (4) attacks usually affecting a single joint ( 90 per cent. of cases); (5) disability often considerable with temporary loss of function of the involved part; (6) complete restitution of joint appearance and function following attacks; (7) para-arthritis, consisting of red tender swellings near a joint (30 per cent. of cases), and frequent involvement of finger pads; (8) absence of general constitutional signs and symptoms; (9) absence of chronic arthritis even when the disease has persisted for years; (10) intracutaneous or subcutaneous nodules ( 9 per cent. of cases); (11) essentially normal laboratory tests including erythrocyte sedimentation rates, blood uric acid determinations, and radiographs of involved joints; (12) adults of either sex affected equally. Joint biopsies were accomplished in three instances (two during acute attacks and one after recovery); these disclosed subacute cellular reactions in the synovial membrane during attacks, but the cellular condition returned to normal on recovery. Findings frequently described as characteristic of rheumatoid arthritis, such as perivascular collections of lymphocytes, pannus formation, and cartilage destruction, were not found. Neither urate deposits nor collections of eosinophils were demonstrated.

Subsequently, twenty-eight cases have been reported by others as examples of palindromic rheumatism (Thompson, 1942; Mazer, 1942; Vaughan, 1943; Ferry, 1943; Paul and Logan, 1944; Grego and Harkins, 1944; Cain, 1944; Wingfield, 1945; Paul and Carr, 1945; Neligan, 1946; Salomon, 1946; Weber, 1946; Hopkins and Richmond, 1947; Scheinberg, 1947). Some of these have conformed to the clinical characteristics as outlined by Hench and Rosenberg; others have not. From the additional reports no new diagnostic data have been proposed and no definite ideas on aetiology have been offered. Chronic fatigue and emotional strain were notable in several cases (Mazer, 1942; Ferry, 1943; Paul and Logan, 1944; Cain, 1944; Neligan, 1946), and in a few these factors appeared to be related temporarily to the onset or exacerbations of symptoms. The transient afebrile episodes of articular and para-articular swellings prompted some (Vaughan, 1943; Weber, 1946) to consider an allergic basis, but no proof has been offered for this supposition.

Already a host of medications, diets, and procedures have been tried therapeutically. These have included: purine-free and low-purine diets, colchicine, cinchophen, allergy diets, epinephrine, ephedrine, benadryl, pyribenzamine, intravenous and oral calcium preparations, histaminase, histamine desensitization, ergotamine tartrate, eradication of foci, febrile reactions with intravenous typhoid vaccine, bacterial vaccines (stock and autogenous), salicylates intravenously, sulphur preparations, and sulphonamides. In general the results from these various forms of treatment have been negative or equivocal. No report has appeared in the literature on the use of gold compounds for palindromic rheumatism.

We have encountered three patients with frequently recurring transient bouts of acute arthritis the clinical features of which conform strictly to the diagnostic criteria of palindromic rheumatism as described by Hench and Rosenberg. Each of these has responded favourably to treatment with soluble gold compounds. 


\section{Case Reports}

Case 1.-A 42-year-old housewife of Irish descent, was first seen on July 16, 1946, because of recurrent acute episodes of arthritis. She was the mother of three children, was obese, jolly, and except for two attacks of gallstone colic and subsequent cholecystectomy, had always been in robust health.

Without previous history of rheumatic complaints the first musculo-skeletal symptoms were experienced in October 1941, while she was accompanying her husband on a strenuous business trip which entailed travelling, loss of sleep, and social entertaining. Without known injury, about mid-day, the right wrist rather suddenly became tender and painful on motion. By dinner time that evening the joint and dorsum of the hand were exquisitely painful, tender, hot, and slightly reddened. She was forced to cancel a dinner engagement and a hotel physician administered hypodermic medication. On the following day the wrist was less sore and swollen and sufficiently comfortable to allow her to go shopping. By evening of the third day (fifty-four hours) all swelling had disappeared, but, as she recalled, some tenderness may have persisted for another twenty-four hours.

Approximately two months later (December 1941) a second attack occurred, the proximal interphalangeal joint of the right index finger being involved. The articular manifestations and the duratien of symptoms were almost identical with the first episode. At the time the patient was under severe emotional stress because her husband, an army reserve officer, was expecting orders for active military service. From December 1941 to July 1946 she continued to have recurrent bouts of transient acute arthritis, the characteristics of each being monotonously similar. The attacks usually came on rather suddenly, starting with an aching in the joint, and within a few hours pain of a bursting type together with swelling, exquisite tenderness, slight redness, and variable amounts of increased local heat developed. Usually the attacks lasted from eighteen to forty-eight hours, but not infrequently tenderness persisted for one or two days longer; a few attacks lasted for only six hours. They recurred at irregular intervals, sometimes two days apart but usually at intervals of one to three weeks. The longest period of freedom was two months, following a cholecystectomy. It was calculated that approximately 350 attacks had been sustained over a period of four years and nine months. Almost all of these had been accompanied by actual joint swelling and slight redness, but in a few attacks only pain and local tenderness were experienced. The attacks came on at any time, and there was no day-time or night-time pattern. Complete restitution of the appearance and function of joints followed each episode, and there were no interval musculo-skeletal symptoms. Between attacks she felt fine, was active socially, and worked hard at home. There had been no general constitutional symptoms, and during the five year period gained $18 \mathrm{lb}$. in weight.

Approximately 95 per cent. of the episodes had involved joints of the upper extremities. Most frequent sites had been the wrists, elbows, and metacarpophalangeal and proximal interphalangeal articulations. The distal interphalangeal joints (except for the thumbs) had been affected rarely. A few attacks had occurred in the knees, ankles, and bunion joints. In approximately 95 per cent. of instances a single joint had been affected; occasionally two, three, or more had been involved. Several times the whole dorsum of the hand had been so swollen and painful that the individual joints involved could not be identified. Para-arthritic swellings, fingerpad involvement, and intracutaneous or subcutaneous nodules had not made their appearance.

Although no definite precipitating factors were recognized by the patient, the initial bouts appeared to have been related to periods of undue emotional strain. No history of allergic manifestations could be elicited, and the attacks apparently were unrelated to the menses.

Physical Examination (July 16, 1946).-Except for obesity (weight $172 \mathrm{lb}$., height 62 inches) and for slight tenderness on deep palpation in the right upper abdominal quadrant, general physical examination revealed no abnormal findings. Save for slightly increased crepitus of both knees, detailed examination of the musculoskeletal system revealed no abnormalities.

Laboratory Data. - These were within normal range. The erythrocyte sedimentation rate was $14 \mathrm{~mm}$. in one hour (Westergren). The erythrocyte count was 4,750,000 per c.mm. of blood and the haemoglobin $12 \cdot 4 \mathrm{~g}$. per $100 \mathrm{c} . \mathrm{cm}$. The total leucocyte count was 9,400 per c.mm., and the differential count revealed 45 per cent. lymphocytes, 8 per cent. monocytes, 44 per cent. neutrophils, and 3 per cent. eosinophils. The filament count was 33 and the non-filament count 11 . Whole blood uric acid was reported as $3.4 \mathrm{mg}$. per $100 \mathrm{c.cm}$. of blood, and the blood cholesterol was $200 \mathrm{mg}$. per $100 \mathrm{c.cm}$. Basal metabolic rates were minus 14 and 16 per cent. Radiographs of the hands and of the sacro-iliac joints were normal.

Interval Course.-From July 16 to Sept. 13, 1946, the patient had seven episodes of acutely painful, swollen joints, three of which were observed by us. One attack in the right ankle was so severe that she had to be transported from the automobile to the office in a wheel chair. Erythrocyte sedimentation rates taken during this interval ranged from 8 to $16 \mathrm{~mm}$. in one hour; one (14 mm. in one hour) was obtained during an acute episode. From Aug. 13 to Sept. 13, benadryl, $50 \mathrm{mg}$. four times daily, was taken without apparent effect.

Previous Diagnosis and Treatment.-The diagnosis of gout was made by two physicians. Trials on purine-free and purine-low diets had failed to influence the clinical course. Colchicine, taken in small doses daily and in full doses during attacks, did not influence the frequency or duration of the attacks. Cinchophen was not tried. The best symptomatic relief during an attack was obtained with the use of large doses of acetyl-salicylic acid, phenacetin compound with codeine, or both.

Chrysotherapy.-Treatment with gold thioglucose was begun on Sept.-13, 1946. After an initial dose of $25 \mathrm{mg}$., a schedule of $50 \mathrm{mg}$. weekly was followed until a total of $1,025 \mathrm{mg}$. had been administered. Maintenance doses of $50 \mathrm{mg}$. every three weeks were then instituted and have been continued. Except for a mild transient stomatitis which lasted for nine days, no toxic reactions have been encountered. 
Course during Chrysotherapy.-The attacks continued with their usual frequency and severity until a total of $47 \overline{\mathrm{mg}}$. of gold thioglucose had been administered. A change in the clinical course then occurred; the bouts became less severe and less intense, and only three episodes were experienced in the subsequent eleven weeks. After a total of $925 \mathrm{mg}$. had been given the attacks ceased. From Jan. 15, 1947, until June 8, 1948, during which time maintenance doses of gold were continued, only one minor bout of pain and swelling in a joint was experienced.

Case 2.-A 42-year-old white male, was first examined on July 24,1946 , because of " migratory arthritis" of twenty-one months' duration. Except for the ordinary childhood diseases he could recall no medical illnesses during his life. A right herniorrhaphy and a haemorrhoidectomy had been performed in 1940. He was married and had three sons ages 18,14 and 12 years.

The patient denied having had any musculoskeletal symptoms before October 1944. At that time he was under considerable nervous stress occasioned by business worries and hard work; for ten years he had averaged fourteen hours at his office daily, six days a week. During that month he experienced an episode of acute pain, tenderness, and limitation of motion in the left shoulder which lasted for four days and then disappeared entirely. From that time he continued to have recurrent attacks of swelling, pain, and tenderness in and about various peripheral joints.

The attacks were characterized by sudden onsets of pain, tenderness, swelling, increased local heat, and varying degrees of redness of a joint or soft tissues in the region of a joint. Often these came on abruptly, the swelling reaching its height within a few minutes. At other times the development was more gradual, and the climax was not reached for several hours; when the onset was gradual, immobility of the part would sometimes prevent the occurrence of actual swelling. The duration yaried from a few hours to two days, but it was never longer than four days. An involved part or joint had always cleared up completely without leaving functional residue. At the beginning the attacks recurred at intervals of every two or three weeks, but gradually the tempo increased, and by the time of examination he was experiencing three to fifteen attacks each week. About 40 per cent, of the episodes began in the late afternoon, between 3 and 5 o'clock.

The patient estimated that 400 attacks had been sustained during a period of twenty-one months. Almost every peripheral joint in the body, large and small, had been involved at one time or another. Not infrequently the disability was sufficiently marked to necessitate the use of a crutch or to prevent his driving an automobile. Initially the involvement was always monarticular, but for the six months before examination multiple joint involvement was frequent. Para-arthritic swellings (including finger pads) were not infrequent; sometimes they occurred alone and sometimes in conjunction with actual articular involvement. Neither intracutaneous nor subcutaneous nodules had been noted. Despite the frequency of attacks there had been no loss of weight, and between episodes he felt well.
- Physical Examination (July 24, 1946).-No abrormal physical findings of significance were noted on examination except those referable to the musculoskeletal $\omega$. system. Twenty-four hours previously an acute attack had occurred in the left metacarpo-phalangeal joints of the second and third digits, and residual swelling and tenderness were noted. An acute episode had begun six $\frac{\bar{\sigma}}{\sigma}$ hours previously in the right knee, and had reached its $\overline{\bar{m}}$ climax at about the time of examination; the joint was $\widetilde{\widetilde{D}}$ moderately swollen, exquisitely tender, painful on motion, $\propto$ and considerably warmer than the opposite knee; full weight-bearing could not be tolerated. The remain-ing peripheral joints were objectively normal, and there? were no abnormal findings referable to the neck or back. $\overrightarrow{\vec{\omega}}$

Laboratory Data. - Repeated erythrocyte sedimentation ${ }_{\sigma}^{\omega}$ rates ranged from 1.5 to $5 \mathrm{~mm}$. in one hour (Westergren). The erythrocyte count was $5,600,000$ per c.mm. of bloodo with $16.6 \mathrm{~g}$. of haemoglobin per $100 \mathrm{c} . \mathrm{cm}$. The totalo leucocyte count was 9,400 per c.mm., and the differential $-{ }_{-}^{-}$ count revealed 46 per cent. lymphocytes, 4 per cent. monocytes, 46 per cent. neutrophils, and 4 per cent.은 eosinophils. Kolmer and Kline tests were negative. Whole blood uric acid was $2.4 \mathrm{mg}$. per $100 \mathrm{c.cm}$., and the blood sugar was $106 \mathrm{mg}$. per $100 \mathrm{c.cm}$. Basal metabolic rates were recorded as minus 12 and minus 16 per cent. Urinalysis was negative. Radiographs of $\vec{\theta}$ the sacro-iliac joints were normal.

Interval Course.-From July 26 to Aug. 26, 1946, benadryl, $50 \mathrm{mg}$. five times daily, was tried without benefit. He continued to have episodes recurring every? two to five days, and approximately half the time he was unable to go to his office. Two erythrocyte sedimentation rates (Westergren) taken during this interval were $2 \mathrm{~mm}$. and $3 \mathrm{~mm}$. in one hour respectively.

Previous Diagnosis and Treatment.-Previous diagnoses $\overrightarrow{\vec{F}}$ had included gout, allergic arthritis, and rheumatoid 3 arthritis. He had been given various medications, but none had altered the clinical course of the disease These included intravenous injections of sodium salicylate and sodium iodide, colchicine, neocinchophen, streptococcus vaccine, injections of thiamine hydrochloride and of vitamin B complex, histamine desensitization, and high-potency vitamin $\mathrm{D}$. He was not sure that salicylates were of benefit in controlling the acute $\frac{\mathrm{O}}{3}$ episodes; more often he had resorted to codeine.

Chrysotherapy.-Treatment with gold thioglucose was? begun on Aug. 26, 1946. After an initial dose of $25 \mathrm{mg}$., weekly doses of $50 \mathrm{mg}$. were administered until a tota으. of $1,175 \mathrm{mg}$. had been given. Maintenance doses of $50 \mathrm{mg}$. every three weeks were instituted on Feb. 4,0 1947, and have been continued. No toxic reactions haven been noted. Erythrocyte sedimentation rates have remained within normal range.

Clinical Course during Chrysotherapy.-No improvement occurred until a total of $625 \mathrm{mg}$. of gold thioglucoseo had been administered. A notable reduction in the number of attacks was apparent thereafter, the frequency being? reduced to approximately one bout every two weeks. After $1,175 \mathrm{mg}$. of gold thioglucose were administered, 0 the attacks ceased. Subsequently, during a sixteen-monthत् period, he has remained free from symptoms except for $\frac{?}{\mathbb{D}}$ four episodes of acute articular pain and swelling (knee 
TABLES

\section{CASE SUMMARIES}

\begin{tabular}{|c|c|c|c|}
\hline & Case 1 & Case 2 & Case 3 \\
\hline $\begin{array}{l}\text { Sex and age } \ldots \\
\text { Duration of symptoms }\end{array}$ & F-42 & M-42 & M-41 \\
\hline $\begin{array}{l}\text { (months) } \\
\text { Total number of attacks }\end{array}$ & 57 & 21 & 24 \\
\hline $\begin{array}{l}\text { (est.) } \\
\text { Usual frequency of attacks }\end{array}$ & 350 & 400 & 200 \\
\hline & $7-21$ & $1-5$ & $2-7$ \\
\hline $\begin{array}{c}\text { attacks (days) } \\
\text { Maximal interval between } \\
\text { attacks (days) .. }\end{array}$ & 60 & 21 & 10 \\
\hline $\begin{array}{l}\text { Duration of attacks (usual) } \\
\text { (hours) } \ldots \\
\text { Percentage } \\
\text { monarticular }\end{array}$ & $18-48$ & $6-96$ & 8-16 \\
\hline $\begin{array}{l}\text { (est.) } \\
\text { Complete restitution of } \\
\text { function after attacks ... }\end{array}$ & 95 & 85 & 98 \\
\hline $\begin{array}{l}\text { Para-arthritis } . . \\
\text { Cutaneous nodules } \\
\text { General constitutional }\end{array}$ & $\begin{array}{l}\mathbf{0} \\
\mathbf{0}\end{array}$ & $\overline{0}$ & $\overline{0}$ \\
\hline $\begin{array}{l}\text { General constitutional } \\
\text { reaction... } \\
\text { Radiographic findings } \ldots \\
\text { Ervthrocyte sedimentation }\end{array}$ & $\begin{array}{l}0 \\
0\end{array}$ & $\begin{array}{l}\mathbf{0} \\
\mathbf{0}\end{array}$ & $\begin{array}{l}\mathbf{0} \\
\mathbf{0}\end{array}$ \\
\hline $\begin{array}{l}\text { Erythrocyte sedimentation } \\
\text { rate (range in mm./hr.) } \\
\text { Other laboratory data }\end{array}$ & $\begin{array}{c}8-16 \\
0\end{array}$ & $\begin{array}{c}1 \cdot 5-5 \\
0\end{array}$ & $\begin{array}{r}7-9 \\
0\end{array}$ \\
\hline
\end{tabular}

RESULTS OF CHRYSOTHERAPY

\begin{tabular}{|c|c|c|c|}
\hline & Case 1 & Case 2 & Case 3 \\
\hline $\begin{array}{l}\text { Total dosage at improve- } \\
\text { ment }\end{array}$ & 475 & 625 & \\
\hline & 925 & 1,175 & 575 \\
\hline $\begin{array}{ccc}\text { ment (est.) } & \ldots & \ldots\end{array}$ & 350 & 400 & 200 \\
\hline $\begin{array}{c}\text { Duration of symptoms } \\
\text { (months) }\end{array}$ & 57 & 21 & 24 \\
\hline $\begin{array}{l}\text { Average number of attacks } \\
\text { per year before treat- } \\
\text { ment } \\
\text { Total attacks during remis- }\end{array}$ & $73 \cdot 4$ & 228 & $83 \cdot 3$ \\
\hline $\begin{array}{ccc}\text { sion } & \cdots & \cdots\end{array}$ & 1 & 4 & $\mathbf{0}$ \\
\hline $\begin{array}{l}\text { Duration of remission } \\
\text { (months) } \\
\text { Average number of attaciss }\end{array}$ & 18 & 16 & 6 \\
\hline $\begin{array}{l}\text { Average number of attacks } \\
\text { per year during remission } \\
\text { Other musculoskeletal }\end{array}$ & 0.66 & 3 & 0 \\
\hline $\begin{array}{l}\text { symptoms during remis- } \\
\text { sion } \ldots\end{array}$ & 0 & 0 & - \\
\hline
\end{tabular}

once, elbow once, wrist twice). Each of these episodes has followed a day of strenuous physical work in his orchard. It is noteworthy that during a severe emotional crisis occasioned by the accidental killing of one of his sons by another while the boys were playing with a rifle, no acute articular episode was precipitated.

Case 3.-A 41-year-old male of Spanish descent was first seen on Aug. 20,1947, because of recurrent pain and swelling of various peripheral joints. Neither his family history nor his past personal history was significant.
Mastoidectomy had been performed at the age of 8 years, and tonsillectomy at the age of 35 . Except for pneumonia as an infant, there had been no other serious medical diseases. He was married and had two children, ages 14 and 7 years.

During childhood he was treated for vague aching in the knees and numbness in the left arm and forearm, but the details were not remembered. No subsequent musculoskeletal symptoms were noted until the onset of the present illness. In July 1945, two years before examination, he began to have transient attacks of pain, swelling, and stiffness in various peripheral joints. These had continued, skipping from joint to joint, until almost every peripheral joint in the body had been involved at one time or another. Attacks had occurred in the wrists, elbows, shoulders, metacarpophalangeal joints, proximal interphalangeal joints, ankles, knees, metatarso-phalangeal joints, and temporo-mandibular and sterno-clavicular joints. The end joints of the fingers had never been involved, nor had there been any symptoms referable to the back or neck.

The individual attacks usually began abruptly, the acute phase lasting approximately eight to twelve hours. As a rule some residual tenderness, aching, and stiffness persisted for two or three days. The episodes usually recurred one to two times each week, and the longest interval without an attack was ten days. The function of joints had always returned to normal following an attack. About 60 per cent. of the episodes were vesperal in time of onset, appearing around 3 to 4 o'clock in the afternoon. Practically every attack had been monarticular, and he recalled only four episodes which involved more than one joint. Approximately 10 per cent. of the episodes were accompanied by para-articular swellings. Neither intracutaneous nor subcutaneous nodules had been noticed. There had been no constitutional symptoms, and he considered himself to be in excellent health. He had sustained approximately 200 attacks over a period of two years.

Physical Examination (Aug. 20, 1947).-No abnormalities were disclosed on general physical examination except for a pedunculated papilloma on the uvula and a left indirect incomplete inguinal hernia. Examination of the peripheral joints and of the back was essentially negative except for those findings referable to the left hand. The metacarpo-phalangeal joint of digit three was moderately swollen, tender on deep palpation, and painful on forced flexion and extension. (An attack had commenced in this joint thirty-six hours previously and was now subsiding.) Observation five days later revealed complete disappearance of all objective manifestations referable to the third metacarpo-phalangeal joint of the left hand, but on this day pain, swelling, increased local heat, and slight redness were present in the left ankle, particularly about the external malleolus.

Laboratory Data.-The erythrocyte sedimentation rate (Westergren) was $9 \mathrm{~mm}$. in one hour, and when repeated three days later was $7 \mathrm{~mm}$. in one hour. The erythrocyte count was 5,490,000 per c.mm. of blood, with $15 \cdot 5 \mathrm{~g}$. of haemoglobin per $100 \mathrm{c.cm}$. The total leucocyte count was 8,000 per c.mm., and the differential count revealed 44 per cent. lymphocytes, 8 per cent. monocytes, 46 per 
cent. neutrophils and 2 per cent. eosinophils. Urinalysis was negative. Kahn and Kolmer tests were negative. Blood uric acid was $3.8 \mathrm{mg}$. per 100 c.cm. Radiographs of the sacro-iliac joints failed to reveal any abnormalities.

Previous Diagnosis and Treatment.-No definite diagnosis had been made previously. For a period of six months, shortly following the onset, he had received subcutaneous injections of some type of vaccine. He had. taken various capsules and tablets, but the exact type of medication received.was not known by the patient.

Chrysotherapy.-Because of our experience with two previous cases, chrysotherapy was begun as soon as the diagnosis was established. Administration of gold thioglucose was begun on Aug. 23, 1947, and after an initial dose of $25 \mathrm{mg}$., a schedule of $50 \mathrm{mg}$. Once weekly was adhered to until a total of $900 \mathrm{mg}$. had been given. At this time a mild skin rash on the lower legs, in the natal crease, and in both axillae developed. Treatment was interrupted for three weeks, and then the patient was placed on maintenance doses of $50 \mathrm{mg}$. every three weeks.

Course during Chrysotherapy.--The attacks continued unabated until $375 \mathrm{mg}$. of gold thioglucose had been administered. During this time the patient kept a detailed record of the attacks, and they recurred at intervals of one to three days. After $375 \mathrm{mg}$. had been given the attacks became less frequent; only five were experienced during the succeeding two months. Complete cessation of attacks occurred when a total of $575 \mathrm{mg}$. had been administered. There have been no recurrences since Nov. 21, 1947, a period of more than six months. During this time, however, he has experienced mild transient aching and stiffness in the shoulders. Erythrocyte sedimentation rates have remained normal.

\section{Comment}

The improvement which occurred during chrysotherapy was striking in each case. A marked reduction in the frequency and severity of the attacks resulted in two cases, and in the third the attacks ceased. In a sti ict sense, however, the remissions were not absolute. Case 1 had a single recurrence during an eighteen-month follow-up period; Case 2 had four recurrences in sixteen months; and although Case 3 had no recurrences in six months he experienced mild transient aching and stiffness of the shoulders. During the periods of quiescence or relative quiescence maintenance doses of gold salts were continued. Whether the attacks will return with their former frequency and severity when treatment is discontinued entirely cannot be answered at this time.

Complete remissions of the disease as well as periods of improvement have occurred spontaneously, without treatment, in a number of previously reported cases. Hench and Rosenberg were able to obtain follow-up reports on twentyseven of their thirty-four cases. Four of these (15 per cent.) had obtained apparent "cures " and were free of attacks for from seven to eleven years; in three, cessation of the attacks occurred spon- 므. taneously; in the other recovery was attributed to treatment with calcium gluconate. In twelve cases $\overrightarrow{\vec{B}}$ (44 per cent.) some change for the better, though not notable, had occurred; in five the attacks became shorter and less frequent, in three they were shorter but as frequent as always, and in four they were less frequent but the duration and severity were the same. It is not likely, however, that the marked improve- $क$ ments in our three cases were spontaneous and $\overrightarrow{0}$ merely coincidental to treatment. In each instance the disease was of relatively long duration, and the $\vec{\omega}$ clinical pattern was well established. In each the clinical course was continuous, with only brief $\stackrel{2}{2}$ spontaneous interruptions in the attacks before $\infty$ treatment, the longest interruption being for two $\vec{\circ}$ months (Case 1).

The facts that psychogenic factors may enhance $\frac{O}{\partial}$ the frequency and severity of the attacks, and that relief of emotional tension may result in improvement, have been observed in several cases. In Ferry's case $\stackrel{\widehat{S}}{\mathcal{C}}$ (1943) the attacks appeared to follow periods of $\overrightarrow{ }$ emotional strain and were not noted when nervous tension was absent. In the case reported by Paul and Logan (1944) the bouts of pain and swelling in the joints most often followed " nervous or angry " upsets. In two of Hench and Rosenberg's thirty-four cases the attacks seemed to be induced by nervous or physical fatigue. One of their $\stackrel{\mathcal{Q}}{\mathcal{Q}}$ patients " adopted a baby, quit worrying about $\vec{F}$ herself and lost her attacks ". Another improved 3 when he " quit the oil business, became a druggist? and began to take phenobarbital daily ". Mazer'so. case (1942) had a remission for a period of four months after orthopaedic shoes had been prescribedo " under conditions of heightened suggestibility at a medical shrine in another country ". Whereas. two of our three patients were under emotional ando physical strain at the time of their initial symptoms (strenuous travelling and social activities in Case 1,을 overwork and business worries in Case 2); these factors did not seem to play a role in the subsequent? course of the disease. It is not likely that then improvement from injections of gold salts resulted from mental suggestion, because in each instance several hundred milligrammes of the drug werew administered before a change in the clinical picture?

The beneficial results from gold salt therapyc raise the question as to whether palindromico rheumatism is a separate entity or an atypical ${ }^{+}$ form of rheumatoid arthritis. The exact position $\frac{0}{0}$ of palindromic rheumatism is not yet established and probably will not be established until more cases? can be observed for longer periods of time anda 
until the pathogenesis of rheumatoid arthritis is better understood. Ropes and Bauer (1945) believe that most, if not all, cases of palindromic rheumatism are really cases of atypical rheumatoid arthritis in which the syndrome of multiple recurrent attacks of pain, redness, and swelling is but a manifestation of the initial stage of the disease. In their experience the majority of patients with the "palindromic syndrome" have evidence of rheumatoid arthritis, such as fusion of the sacro-iliac joints or other characteristic radiographic changes, or they finally develop a progressive symmetrical joint disease.

Certainly rheumatoid arthritis may present variable clinical patterns. Not all cases conform to the so-called typical picture of insidious onset, chronic progression (with or without incomplete remissions), and inevitable crippling. Our concept of the disease has been broadened considerably during the past few years, and atypical forms with various types of onsets and clinical courses are being recognized with increasing frequency. Some cases of rheumatoid arthritis begin in a hit-and-miss fashion, with periodic bouts of transient arthritis which clear up completely between attacks and which initially fail to leave joint residues. It may take months or even years for such cases to settle down to a progressive crippling disease. Hench (1947) has recognized this atypical form as " episodic rheumatoid arthritis" and believes that it may be validly differentiated from palindromic rheumatism. He contends that in "episodic rheumatoid arthritis" the attacks tend to recur in favourite sites; para-arthritis is absent or rare, and involvement of finger pads never occurs; the attacks tend to last longer, occasionally weeks; the interval between episodes is often shorter, the attacks sometimes running together; constitutional symptoms and signs are likely to be present.

If "palindromic rheumatism" and "episodic rheumatoid arthritis" are distinct entities, clinical differentiation is of considerable importance. Each has an entirely different prognosis. From the practical standpoint, however, it is often difficult and sometimes impossible to make such differentiation. After taking all differentiating points into consideration the physician frequently ends, up with some points for and some against each diagnosis. For example, we now haye under observation two patients with transient articular reactions which affect individual joints for such short periods of time as a few hours or a few days. But in each, some finding characteristic of rheumatoid arthritis is also present which prevents a diagnosis of palindromic rheumatism if strict criteria are adhered to. A third case under observation had early features typical of palindromic rheumatism, but thirteen months after the onset developed progiessive joint changes characteristic of rheumatoid arthritis. Such experiences suggest to us that palindromic rheumatism probably represents an atypical form of rheumatoid arthritis in which the usual characteristics have not yet become manifest.

If further trials with chrysotherapy in cases of palindromic rheumatism substantiate the favourable results obtained in the three cases reported herein, some weight may be added to the contention that this syndrome represents merely an atypical form of rheumatoid arthritis. However, the results could be interpreted as meaning only that another form of arthritis may respond to gold salt therapy. In addition to rheumatoid arthritis, pleuropneumonia-like arthritis of mice and some cases of psoriatic arthritis are known to be benefited by chrysotherapy.

\section{Summary}

Three cases with the typical clinical characteristics of so-called palindromic rheumatism are reported. Each case responded favourably to treatment with soluble gold compounds.

\section{REFERENCES}

Cain, J. C. (1944). J. Amer. med. Ass., 125, 1037.

Ferry, J. L. (1943). J. Indiana med. Ass., 36, 348.

Grego, J. G., and Harkins, H. N. (1944). J. Mich. med. Soc., 43, 401.

Hench, P. S. (1947). Arizona Med., 4, 62.

-, and Rosenberg, E. F. (1941). Proc. Mayo Clin., 16, 808.

- , (1944). Arch. intern. Med., 73, 293.

Hopkins, J. J., and Richmond, J. B. (1947). Ann. intern. Med., 26, 454.

Mazer, M. (1942). J. Amer. med. Ass., 120, 364.

Neligan, A. R. (1946). Brit. med. J., 1, 205.

Paul, W. D., and Carr, T. L. (1945).' Arch. phys. Med., 26, 687.

and Logan, W. P. (1944). J. Iowa med. Soc., 34, 101.

Ropes, M. W., and Bauer, W. (1947). New Engl. J. Med., 233, 618.

Salomon, M. I. (1946). N.Y. St. J. Med., 46, 622.

Scheinberg, D. (1947). J. Tenn. med. Ass., 40, 260.

Thompson, J. L., Jr. (1942). Med. Ann. Distr. Columbia, 11, 189.

Vaughan, W. T. (1943). J. Allergy, 14, 256.

Weber, F. P. (1946). Lancet, 251, 200.

Wingfield, A. (1945). Brit. med. J., 2, 157.

Aurothérapie du Rhumatisme dit Palindromique RÉSUMÉ

.Les auteurs décrivent trois observations de malades présentant les caractéristiques cliniques typiques du rhumatisme dit palindromique. Chacun a réagi favorablement au traitement par des sels d'or solubles. 